Fourth International Conference on Sustainable Construction Materials and Technologies http://www.claisse.info/Proceedings.htm

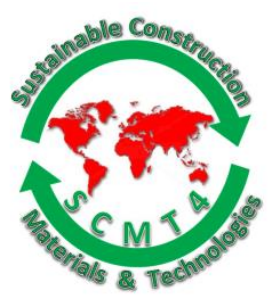

SCMT4

Las Vegas, USA, August 7-11, 2016

\title{
Sustainable Renewal Plan for RC Slab of Expressway Steel Girder Bridges in Japan
}

\author{
Hideaki Sakai ${ }^{1 \mathrm{a}}$, and Izumi Tanaka ${ }^{1 \mathrm{~b}}$ \\ ${ }^{1}$ Engineering/Construction Headquarters, Central Nippon Expressway Co. Ltd., JAPAN. \\ ${ }^{1 a}$ Email: 〈h.sakai.aa@c-nexco.co.jp>, ${ }^{1 b}$ Email: <i.tanaka.aa@c-nexco.co.jp>.
}

\begin{abstract}
More than fifty years have passed since the first roadway opened for service in Japan's network of intercity expressways managed by expressway companies. As with the roadways, the expressway bridges are aging and deteriorating because of increases in traffic volume and loading, harsh environments and other factors. Therefore, a renewal plan for bridges was drafted to address this issue. The renewal plan will implement large-scale renewal, reinforcement and repair of bridges which cannot satisfy bridge performance requirements over the long term with the usual small-scale reinforcement and repair alone because of advanced deterioration caused by such factors as salt damage and fatigue due to traffic loading. The main works include replacing reinforced concrete (RC) slabs of steel girder bridges with precast prestressed concrete (PC) slabs, replacing salt-damaged and deteriorated concrete surfaces with sound concrete structures, reinforcing bridges containing corroded prestressing steel and repairing fatigue cracks in steel structures. In sustainable renewal plan for $\mathrm{RC}$ slab of steel girder bridges, if the severe deterioration occurs in the RC slab, that will be renewed to high durability precast PC slab. In the design of the new PC slab, the structure and material is determined in consideration of the degradation factors of the old RC slab. Also, materials of the new PC slab are demanded the high durability against salt damage. The schedule of works will take around 15 years to implement. The cost is 1,640 billion yen (about 13 billion US\$).
\end{abstract}

\section{INTRODUCTION}

More than fifty years have passed since the first roadway opened for service in Japan's network of intercity expressways managed by expressway companies, which now stretches out to more than $9,000 \mathrm{~km}$. The bridges on these expressways are aging and deteriorating because of increases in traffic volume and loading, harsh environments and other factors. To address this, expressway companies in Japan drafted a new renewal plan for expressway bridges that will conduct large-scale renewal, reinforcement and repair that will enable the continuous and sustainable use of expressways into the future. This paper will discuss this renewal plan. 


\section{DETERIORATION OF EXPRESSWAY BRIDGES}

Inspections of expressway bridges revealed that the main factors causing deterioration were fatigue, salt damage, alkali-silica reaction and their combined effects. From among 19,608 expressway bridges, the deterioration factors based on the judgment index shown in Table 1 applied to 8,404 bridges. This implies that fully $43 \%$ of bridges have deteriorated due to causes described in Table 1 [Sakai, H. 2015].

Table 1. Deterioration Mechanism, Judgment Index

\begin{tabular}{|c|c|c|c|}
\hline $\begin{array}{c}\text { Deterioration } \\
\text { mechanism }\end{array}$ & Estimation item & Judgment index & Number of bridges \\
\hline Fatigue & $\begin{array}{c}\text { Cumulative no. of 10-ton } \\
\text { equivalent axles for large } \\
\text { vehicle traffic }\end{array}$ & 30 million axles or more & 3,270 \\
\hline $\begin{array}{c}\text { Salt damage } \\
\text { (Antifreezing agent) }\end{array}$ & $\begin{array}{c}\text { Cumulative amount of } \\
\text { antifreezing agent sprayed }\end{array}$ & 1,000 t/km or more & 4,862 \\
\hline $\begin{array}{c}\text { Salt damage } \\
\text { (Airborne salt) }\end{array}$ & Distance from coast & $\begin{array}{c}\text { Specifications for Highway } \\
\text { Bridges Part III Section 5.2 } \\
\text { Class II or higher }\end{array}$ & 392 \\
\hline $\begin{array}{c}\text { Salt damage } \\
\text { Salt in concrete) }\end{array}$ & Inherent salinity & $\begin{array}{c}\text { Use of beach sand }+ \\
\text { Pre-chloride content limit } \\
\text { (before 1986) }\end{array}$ & 924 \\
\hline $\begin{array}{c}\text { Alkali-silica } \\
\text { reaction }\end{array}$ & Cracking condition & $\begin{array}{c}\text { Appearance of cracks } \\
\text { indicative of ASR }\end{array}$ & 452 \\
\hline $\begin{array}{c}\text { Composite } \\
\text { deterioration }\end{array}$ & - & $\begin{array}{c}\text { Multiple deterioration } \\
\text { mechanisms present }\end{array}$ & 1,496 \\
\hline
\end{tabular}

\section{OVERVIEW OF THE NEW RENEWAL PLAN}

A new renewal plan was drafted based on the state of deterioration and the factors causing these deteriorations as shown in the previous section. The plan was designed to implement the measures shown in Table 2 [NEXCO-CENTRAL 2015]. The cost required for this plan was estimated to be 2,170 billion yen (about US\$19 billion), and the schedule of works will take around 15 years to implement. In this paper, the renewal of RC floor slabs of steel girder bridges will be discussed.

Table 2. Overview of the New Renewal Plan

\begin{tabular}{|c|c|c|c|c|}
\hline $\begin{array}{c}\text { Measures } \\
\text { classification }\end{array}$ & Structure & Method & Length $(\mathrm{km})$ & Estimated project cost \\
\hline \multirow{3}{*}{ Renewal } & Floor Slab & Replacement & 224 & 1,650 billion yen \\
\cline { 2 - 5 } & Girder & Replacement & 13 & 100 billion yen \\
\cline { 2 - 5 } & \multicolumn{2}{|c|}{ Subtotal } & 237 & 1,750 billion yen \\
\hline \multirow{2}{*}{$\begin{array}{c}\text { Reinforcement } \\
\text { and } \\
\text { Repair }\end{array}$} & Floor Slab & $\begin{array}{c}\text { High performance } \\
\text { waterproof, etc. }\end{array}$ & 359 & 160 billion yen \\
\cline { 2 - 5 } & Girder & Reinforcement, etc. & 151 & 260 billion yen \\
\hline \multicolumn{2}{|c|}{ Subtotal } & 510 & 420 billion yen \\
\hline
\end{tabular}




\section{DETERIORATION OF THE RC FLOOR SLAB OF STEEL GIRDER BRIDGES}

Inspections of existing bridges revealed that the main factors causing deterioration of the RC floor slabs of steel girder bridges are fatigue from vehicle traffic through the bridge and salt damage due to antifreezing agents and airborne salt. The stages of development and mechanisms of deterioration caused by floor slab fatigue are shown in Table 3. Degradation due to salt damage from antifreezing agents are shown in Photos 1 and 2

\section{Table 3. The Stages of Development and Mechanisms of Deterioration Caused by Floor Slab Fatigue}

\begin{tabular}{|c|c|c|}
\hline Stage & Development and mechanisms of deterioration & Deterioration progress figure \\
\hline 1 & $\begin{array}{l}\text { Initial service stage } \\
\text { No harmful cracks are found at the initial service stage. }\end{array}$ & \\
\hline 2 & $\begin{array}{l}\text { Unidirectional cracks occur } \\
\text { Cracks on the floor slab occur in one direction due to drying } \\
\text { shrinkage, etc. Because the shrinking slab is restrained by steel } \\
\text { girders, etc., cracks perpendicular to the bridge axis develop } \\
\text { easily. }\end{array}$ & \\
\hline 3 & $\begin{array}{l}\text { Grid-like pattern cracks propagate } \\
\text { Lengthwise and crosswise cracks occur alternately and cracks } \\
\text { in a grid-like pattern increase. Lengthwise and crosswise } \\
\text { cracks gradually advance due to the effects of live load, } \\
\text { accompanied by the gradual degrading of shear stiffness and } \\
\text { torsional shear stiffness. }\end{array}$ & \\
\hline 4 & $\begin{array}{l}\text { Cracks penetrate to the top surface } \\
\text { While the bidirectional cracks propagate, new cracks further } \\
\text { propagate until they form a grid-like pattern. Moreover, } \\
\text { flexural cracks penetrate through the floor slab due to cyclic } \\
\text { traffic loading. }\end{array}$ & \\
\hline 5 & $\begin{array}{l}\text { Degradation of shear resistance on the crack fracture } \\
\text { Shear resistance degrades as the abrasion phenomenon occurs } \\
\text { on the crack fracture surface. Particularly significant when } \\
\text { water is present. Rainwater penetrating into the through cracks } \\
\text { causes efflorescence to form deposits on the bottom surface of } \\
\text { the floor slab. Leaching rust from rebars adheres to the surface } \\
\text { as well. }\end{array}$ & \\
\hline 6 & $\begin{array}{l}\text { Concrete spalling occurs } \\
\text { Although the increase of crack density stops when the } \\
\text { bidirectional cracks develop to about } 20 \text { to } 30 \mathrm{~cm} \text { squares, } \\
\text { punching shear strength degrades significantly such that wheel } \\
\text { loads exceeding this strength cause concrete to spall. }\end{array}$ & \\
\hline
\end{tabular}



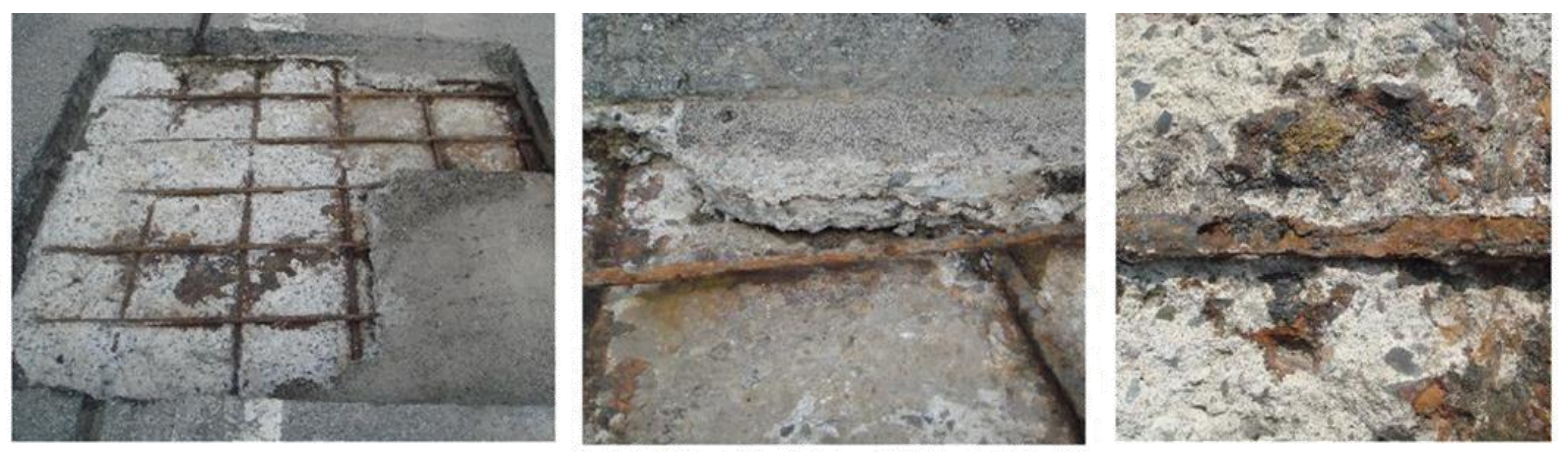

Photo 1. Corrosion of Rebar and Spalling of Concrete on the Upper Surface of Floor Slab
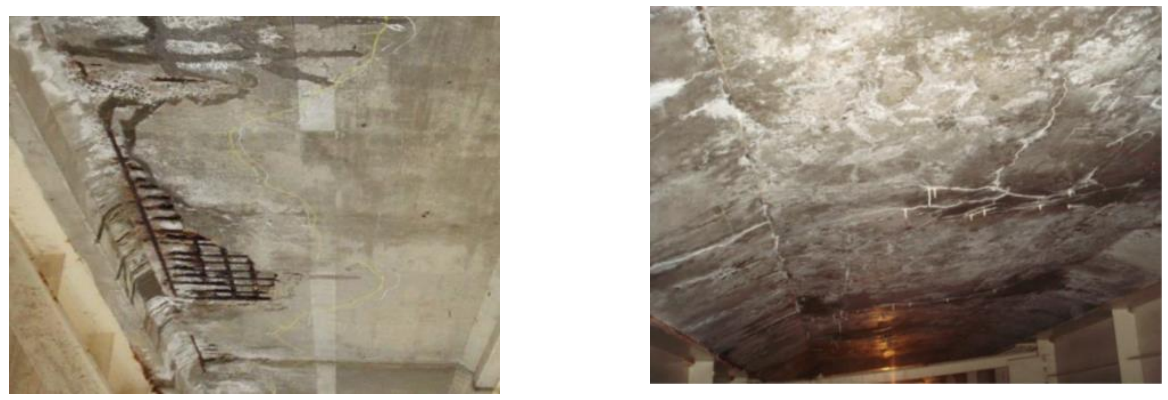

Photo 2. Corrosion of Rebar and Spalling of Concrete on the Lower Surface of Floor Slab

\section{THE RENEWAL PLAN FOR RC FLOOR SLAB OF STEEL GIRDER BRIDGES}

The renewal plan for RC floor slab of steel girder bridges is a program to replace current RC floor slabs, depicted in Figure 1, with new ones when abnormalities in the floor slab due to fatigue, salt damage and other factors have advanced to a stage where its structural performance falls below the required performance for expressway bridge slabs.

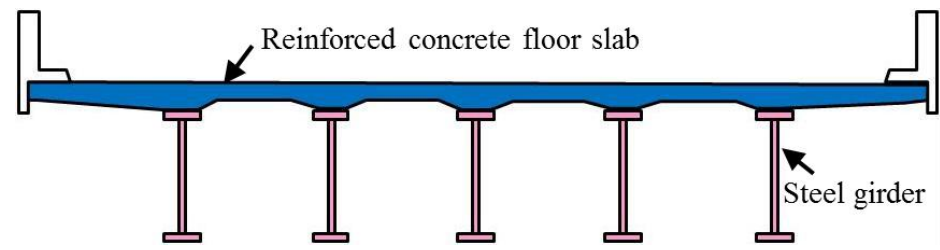

Figure 1. Cross Section of Steel Girder Bridge with RC Floor Slab

\section{Design and construction policy for renewal slab}

The slab for use in the renewal will be designed and constructed based on the policy stated below, which is currently under consideration.

i. The renewal slab will use precast PC slab since, according to previous research, it is safer against fatigue and has higher durability against salt damage and carbonation compared to present RC slabs and can be constructed easily.

ii. When designing the renewal slab, the causes and state of degradation in the target structure will be investigated and the performance requirements will be set based on the investigation. The renewal slab 
materials and structure will be set such that its performance during its design service life does not fall below the performance requirements because of degradation. The objective of design service life of the renewal slab is set to 100 years, because design service life of the new expressway bridges is set to 100 years in Japan.

iii. When selecting materials and structure for the renewal slab, new technology and construction methods will be actively adopted and efforts will be made to reduce costs and shorten the construction period.

\section{Structure of precast PC slab}

The precast PC slab for use in the renewal will be fabricated at the shop or onsite yard with prestressing forces introduced through a pre-tensioning system and will be transported to the bridge site by trailer trucks or similar means for erection. The slab will normally be segmented into a width (of about $2-2.5 \mathrm{~m}$ in general) in the longitudinal direction of the bridge that is transportable by trailer trucks or similar means. Further segmentation in the bridge transverse direction may also be done when the bridge roadway is wide or when road traffic control during construction calls for it. In general, joints between slabs will be built in-situ as RC structures using loop rebar joint. An example cross section of the precast PC slab and joints between slabs using loop rebar joint is shown in Figure 2, 3 and 4. And an example construction of the precast PC slab is shown in Photo 3 and 4.

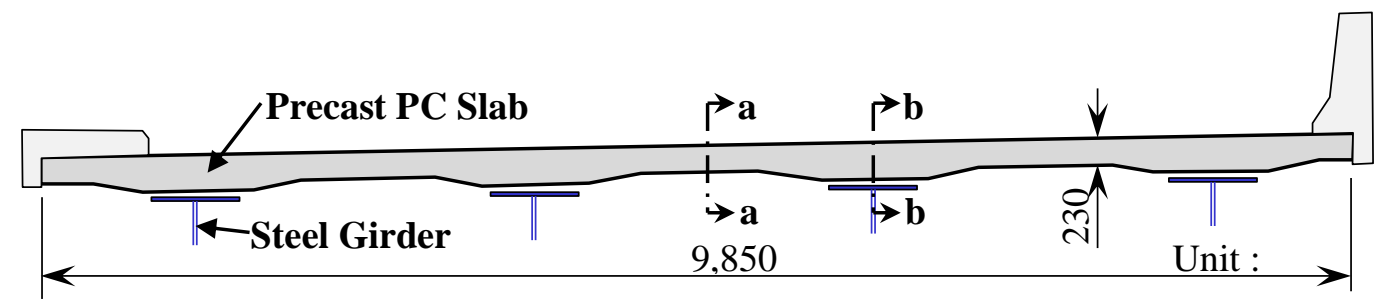

Figure 2. Cross Section of Precast PC slab

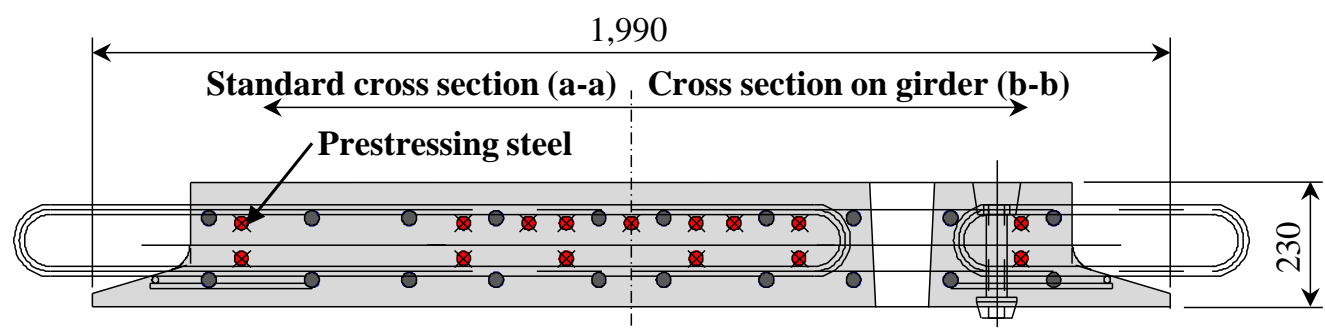

Figure 3. Cross Section of Precast PC slab Segment

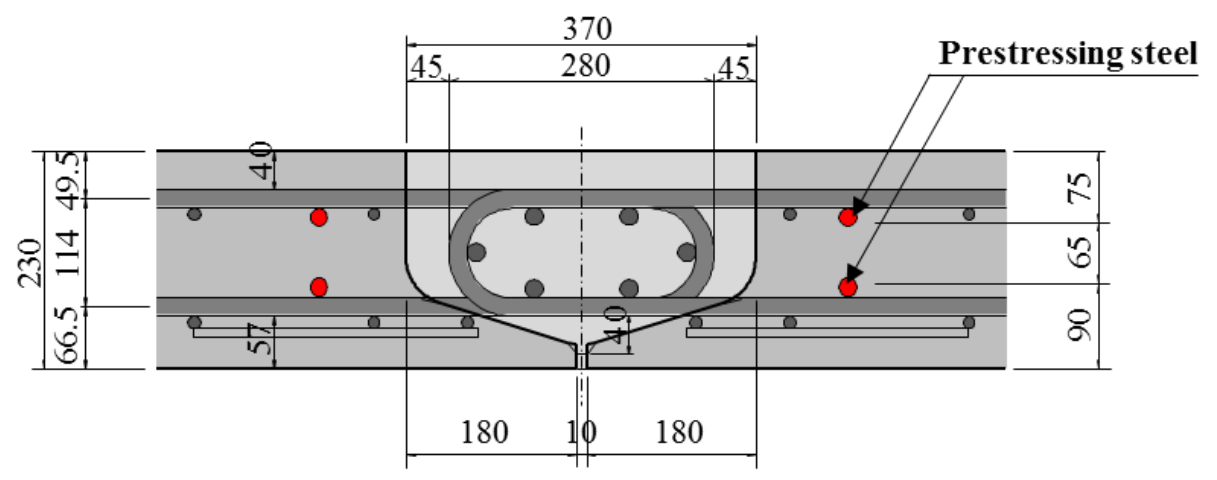

Figure 4. Cross Section of Joints between Slabs using Loop Rebar Joint 
There is negative moment at the support regions of the new slab, as Fig. 2. In the design, the new slab is not allowed the occurrence of cracks in the serviceability limit state. Therefore, it is possible to prevent corrosion due to generation of cracks, and the slab upper surface is covered waterproofing as a multi-layer protection. In addition, the deterioration does not have been confirmed after 15 years in the same type of slabs. In the inspection for maintenance, it is necessary to check for deterioration of occurrence of the pavement surface because it is difficult to visually occurrence of cracks on the surface of slab.

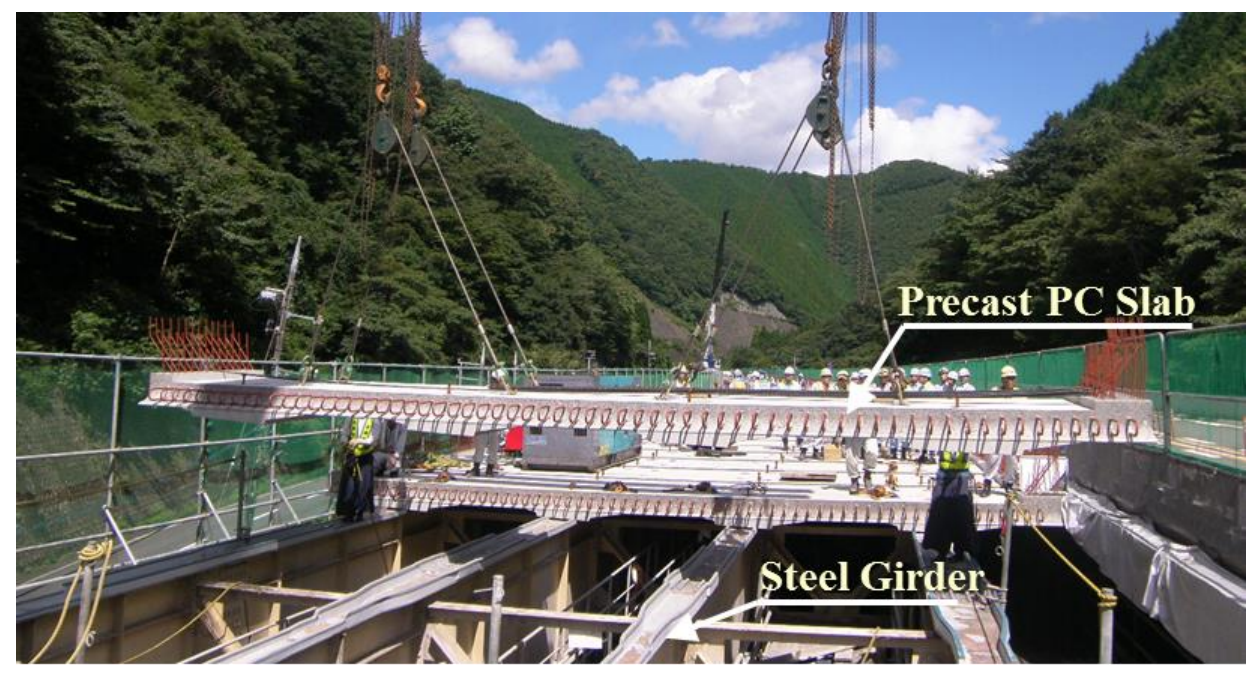

Photo 3. Removing of Old RC Slabs

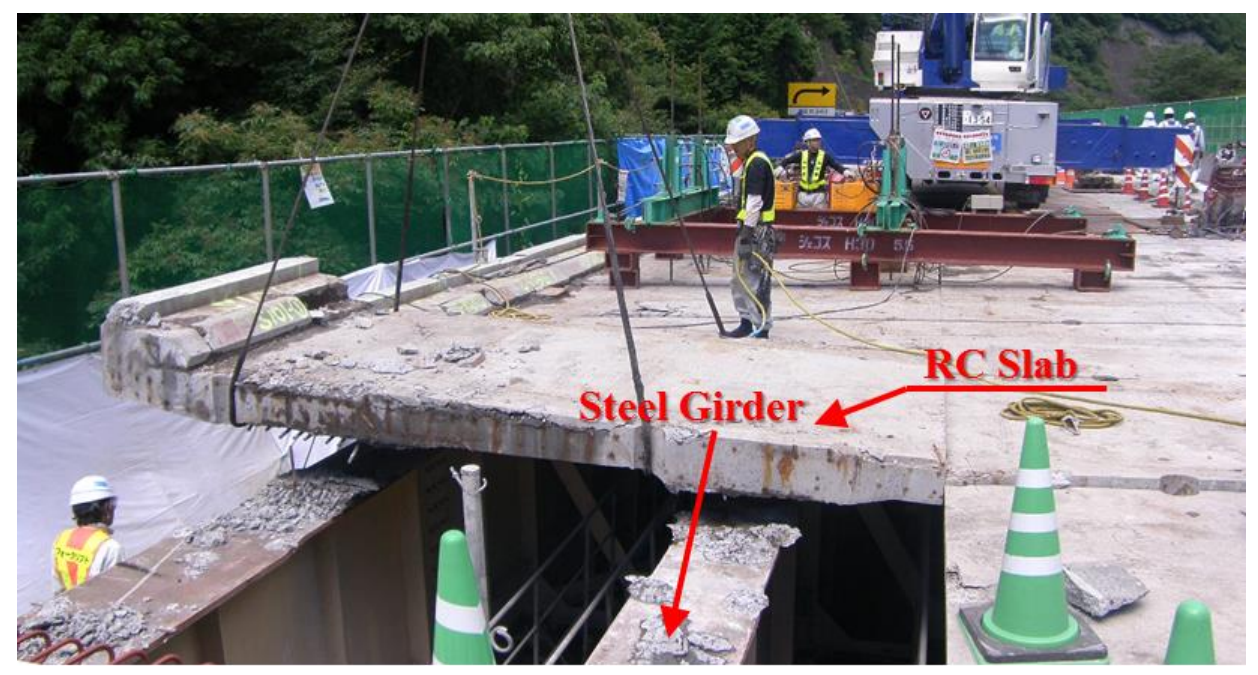

Photo 4. Installation of New PC Slabs

\section{Materials of precast PC slab}

The RC slabs targeted for renewal are members which require replacement because of degradation from fatigue, salt damage and other factors. Thus, the precast PC slabs for use in replacing them will have to be designed so that degradation similar to those found in the existing slabs will not occur. In particular, when designing renewal precast PC slabs subject to the environment and which may degrade from salt damage, suitable materials should be used to ensure their durability. Material selection is to be conducted using the policy stated below. 
i. When selecting concrete ingredients and mix proportion, measures will be taken to reduce chloride ion diffusion coefficient in the concrete. Examples of such measures include lowering the water-cement ratio or using admixture that can reduce the diffusion coefficient. Possible admixtures include ground granulated blast-furnace slag [Sakai, Yokoyama and Furukawa 2002] and fly ash.

ii. When steel contained in the concrete (rebars and prestressing tendons) can potentially corrode even after implementing the measures given in the previous paragraph, the use of epoxy-coated or stainless steel rebars and FRP (Fiber Reinforced Plastics) reinforcements will be considered. Similarly, the use of epoxy-coated or stainless steel tendons and FRP tendons will be considered.

\section{CONCLUSION}

This paper discussed the outline of the new renewal plan for expressway bridges. The renewal plan is a program to implement measures that extend the design service life of target bridges to roughly 100 years. Therefore, when implementing these measures, identifying the causes of abnormalities in the target bridges and performing their design and construction such that the same abnormalities do not develop afterward is utmost importance. Accordingly, plans for the future include investigating specific strategies for their design and construction.

\section{REFERENCES}

Sakai, H. "Renewal Plan of NEXCO." Proceedings of 43rd PC Technology Workshop, Japan Prestressed Concrete Institute, In Japanese.

NEXCO-CENTRAL. "Renewal Plan of NEXCO EAST, CENTRAL and WEST." Central Nippon Expressway Co. Ltd., 18 pages. In Japanese.

Sakai, H., Yokoyama, H. and Furukawa, R., "Performance Tests of Precast Prestressed Concrete Slabs Produced Using Ground Granulated Blast-Furnace Slag $\left(6,000 \mathrm{~cm}^{2} / \mathrm{g}\right)$." Proceedings of the 1st fib Congress, 355-362. 